\title{
Discussion on Administrative Law protection for Pension Rights and Interests of the Lost Only-Child Elderly in China
}

\author{
Zehua Feng \\ Faculty of Law \& Faculty of Intellectual Property, Jinan University, No.601,Huangpu West Rd, \\ Guangzhou, Guangdong Province, China 510632 \\ email:fzh912@qq.com
}

\begin{abstract}
Lacking of shelter and care from their children, Chinese lost only-child elderly are impoverished and their mental state compared to older people in general are more fragile and sensitive. They have even united themselves for self-help, while their efforts have been often unhelpful. Their scale has been increasingly expanding and risen to many serious social problems. Appearance of lost only-child old man people and vulnerability of protection for those elderly is mainly due to the faultiness of Birth Control Policy, lack of government finance and imperfect social security system. Chinese government should establish a mechanism to increase and maintain the value of administrative compensations, strengthen administrative pay and protection of administrative contracts, broaden administrative relief channels for the elderly, and effectively protect the pension interests of the lost only-child elderly.
\end{abstract}

Keywords-The lost only-child elderly, Pension rights and interests, Administrative law protection.

\section{Introduction}

On October 29, 2015, the Chinese government decided to implement the policy about Chinese citizens can have two children since 2016 [1]. However, before 2016, the implementation of China's family planning policy lead to a lot of lost only-child old man emerging. Generally speaking, the lost only-child elderly refers to those elderly who have no adopted and natural children because their only one child--the Birth Control Policy limits their children to only one-has died in an accident and female one has lost fertility. Recently, more and more attentions to the lost only-child elderly are paid in China and thus it is urgent to strengthen pension rights of these elderly. In addition, the lost only-child elderly implore the government to provide them with a low cost centralized community, to introduce appropriate laws and regulations as soon as possible and to determine a private institutions that govern groups of the lost only-child families, so that they have somewhere to turn to help [2].

\section{The status of Chinese lost only-child elderly}

First of all, the scales of the lost only-child elderly are large. In 2010, according to the domestic health statistical yearbook announced from China's Ministry of Health, the number of the lost only-child families has reached to one million and increased by 7.6 thousand annually, supposing that there are 40 deaths due to disease among one million of at least 190 million only-child aged 15 to 30 years. Since 2010, even if the increasing number of only-child and the number of deaths among them has been negligible, there will still be ten million families of the lost only-child families by 2035 [3]. This trend, indicating that the groups of lost only-child old man have become a huge social groups, leads the pension problem of the lost only-child elderly to the increasingly prominent social problems no longer a handful of only the individual problems of individual families, as 
well as brings severe tests into the imperfect social security system.

Secondly, the economic situations of the lost only-child elderly are relatively poor. City lost only-child elderly groups generally have pension and wage income or rely on local social assistance and subsidies to maintain basic life, but government supporting standards are low. The information released by the State Planning Commission indicates that since 2014 government's subsidies have been 340 yuan per person per month in town and 170 yuan in rural, and that all levels of regional governments have established various supporting standards in accordance with own regions, while these weak supports given to the lost only-child elderly groups are just like a drop in the bucket. The rural lost only-child elderly groups are particularly poor in their economical conditions, and even some who are ignorant of the pension policies almost have no economic sources and might not have abilities to tackle food and clothing problems. In addition, among those families of the lost only-child elderly where children have died of the sickness, some have incurred huge debts for saving their children' life, or some have owed huge amounts of medical debt for treatments of perennial triggered depression. Adult children-family supports of the lost only-child elderly-leaving will not enable the lost only-child elderly to buffer offspring feedback and economic support and will lead them into one disaster after another.

Finally, the mental state of the lost only-child elderly is extremely sensitive and fragile. The biggest risk of family with a single child is that their only child maims and dies, because departure of their child is equivalent to collapse and destruction of family with complete and stable structure. We outsiders have no personal experience to the emotion of the lost only-child elderly that it is full of regretful, memorable, remorseful and hateful to the past, especially sad, depressed, evasive and disgusted to the reality and fearful and hopeless to the future. In addition to the pain of lost their children, they also bear suffering of body disease, economic difficulties, the nervous conjugal relations, social status discrimination and future empty nest life pressure and so on. The lost only-child elderly are more afraid of illness, because they fear that they cannot afford to pay for medical expenses and have no one to accompany and to sign their needy operations. According to statistics, among the lost only-child elderly aged more than fifty years, over half of them suffer from various twilight chronic diseases, $15 \%$ of them get paralyzed and advanced cancer, and more than $60 \%$ of them suffer from varying degrees of depression due to cannot withstand the pain of losing child, as well as individual elderly has suicidal and self closing phenomenon [4].

\section{The Cause of the issue on Chinese lost only-child elderly}

First, there are defects in the Birth Control Policy. Chinese traditional Birth Control Policy advocates a couple to bear one child. Over the years, the popular of the country have shrunk by over 0.4 billion, which is effectively alleviate to the pressure of excessive population and resource allocation, and effectively promote the rapid economic development and social progress of civilization. However, during over 30 years when the old family planning policy implements, most attentions to the population reduction, pressure on resource demand easing, the economic development and social progress have been paid, but few attentions to the impact on family structure caused by changes of the population quantity, proportion and dependency ratio among each age segment and risk of lost only-child families have been paid. Currently, the lost one-child families will reach to ten million, which is bound up with the Birth Control Policy. For thousands of years, the traditional idea that more children bring more happiness are already rooted in the hearts of the people deeply, Chinese current pension insurance system is imperfect, pension funds are in serious shortage, and China have entered into the aging society where aging populations are so large that countries can't afford all pension problems, so endowment for 
elderly by families still occupy dominant position in old-age security system. Tracing to its source, lost only-child families are plagued by growing crises and the biggest one lies in children' death which basically weaken their endowment function or even to paralysis.

Second, China bring low investment into financial support for the lost only-child elderly. According to 2001-2013 China Finance Statistics Yearbook sorting out and analyzing, fiscal expenditure on social security shares from 2000 to 2013 stagnantly hover between the $9 \%-12 \%$, far lower than the average levels of $30 \%$ to $50 \%$ in developed countries and social security contribution rate in most developed countries is lower than in China, while pension replacement rate much higher than China. Problems reflect in the national finance lacking of supports and compensations for social security funds. Specifically, following the announcement jointly released by the National Population and Family Planning Commission and the Ministry of Finance in 2007, the government provided each lost only-child old man who meet the relevant conditions with assistance payments no less than 80 yuan to 100 yuan per month until they die [5]. After August 2007, in response to the central call, each local government has introduced subsidy standards adapting to its own local conditions. Beijing's subsidy standards for families with children disabled or disabled are 160 yuan per person per month, while the standards of vast numbers of provinces are 120 yuan per person per month in families with children disable and 150 yuan per person per month in families with children died. Since January 1, 2013, Yancheng has improved grants per person per month from 150 yuan to 500 yuan. Efforts to support vary between various local governments, the ranges of policy are uneven and the general policy is only for the household population. It is difficult for the migrant workers who lose their only child to get any assistance measures.

Third, the social security system is imperfect. First, the coverage of social security in China is relatively narrow. Pension funding for lost only-child families derives from two aspect-pensions and special assistance payments. Our governments have strengthened the construction of social security system taking the social insurance as the center after the policy of reform and opening to the outside world, but the implementation subjects of the system mainly refer to urban workers. Those citizens without formal job and huge farmers would not enjoy the social security and the elderly people among them when losing their only child will carry a heavy financial burden. China still has a majority of lost only-child families who never enjoy subsidies for the lost only-child families. The last layer of the safeguarding for lost only-child families is social pension, while less than half of the lost only-child elderly receive the subsidies for the lost only-child families and the pension insurance coverage is narrow, which gives the lost only-child families a greater economic burden. Secondly, China has no well-functioning social pension service. At present, Chinese main bodies to provide social endowment resources include community service institutions, public and private pension institutions, proprietary pension area for the lost only-child elderly and so on. Data shows that by the end of 2010, there are 0.12 million comprehensive community service centers with daycare services built across the country, which provide about 0.12 million residential beds and daycare beds 0.47 million [6]. According to statistics, by 2010 the total number of beds in the national pension institutions have account for only $13.26 \%$ of the country's elderly population, which is far below the level of developed countries, and even lower than the level of some developing countries. In 2011, all kinds of pension services in the country have reached to a total of 40868 and have 35.32 million beds [7]. From the data, we can draw a conclusion that there are large gap between the pension needs of the whole society and the basic pension services. 


\section{Chinese protection path of administrative law for pension rights and interests of the lost only-child elderly}

First, a mechanism to increase and maintain the value of administrative compensations should be established. As is well known, the rights and the corresponding obligations must be equal. Put another way, just as there are no obligations without the corresponding rights, there are no rights without the accompanying obligation [8]. The lost only-child family has been very strict adherence the obligations of the Birth Control Policy, adhered to bear only a child and made great contributions to the national implementation of populations for the state to control population growth, resources and the optimal allocation, but now they fall into the abyss due to the death of their only child and therefore are deserving of compensations from governments which are responsible for them. In 2008 the country began the implementation of the Pilot Schemes, including an important provision that the lost only-child elderly should obtain not less than 100 yuan assistance payments given by the government per person per month until death. Accordingly, each region has formulated of the corresponding compensation standards in accordance to the local actual situation, but the definition of assistance payments is unclear, so the each regional assistance payments are no other than 100 yuan per month, while Beijing monthly assistance payments are just 200 yuan. In recent years, although the financial support standards have improved. Specifically, the monthly grants per person in town will be increased to 340 yuan and in rural will be up to 170 yuan [9], which can in some extent to resolve some difficulties of the life of lost only-child elderly, but for these elderly it is still a drop in the bucket. With the rising prices and the cost of living rising, it is recommended for each regional governments to establish the mechanism to increase and maintain the value of administrative compensations in accordance to actual situation and make corresponding adjustments to the standards of issued grants based on the evaluation of rate of rising prices in the region to meet the basic survival needs of the lost only-child family.

In addition, the government should also set up special pension funds spent on the health care and other living expenses of the lost only-child elderly. As a result of a number of province's social compensation fee collection standards and the large discretion space, the phenomena of rent-seeking to rights and corruptions are easy to breed and spread. In the process of fiscal collecting, phenomena that accounts that should be recorded are off-the-books or accounts are less than reality often occur. And so-called social maintenance fees has become the main township financial revenue, while the purpose of these huge social maintenance fees and whereabouts is still a mystery. To curb this phenomenon, social maintenance fees handed by the people who violate the Birth Control Policy can be used to establish the special family pension fund. According to statistics, the total number of annual social maintenance fees levied across 31 inland provinces and cities have reached to more than 200 billion. From the moral point of view, it is the most suitable to use these social compensation fees to compensate the lost only-child family which comply with the Birth Control Policy and the impoverished lost only-child elderly, which is not only in a certain extent to reflect that Chinese government concern for the lost only-child elderly and may prevent from abusing social compensation fees and play real financial significance of these fees.

Second, Chinese mechanism of administrative payment should be improved. First, the zero threshold Public Pension Hospital should be implemented. As for the lost only-child elderly, having children against aging has become a luxury, so they have to rely on the government and the community. But according to the current objective conditions of Chinese 
nursing home, it is not easy to stay in the nursing home. There is data showing that Chinese pension industry-where there are only 17 beds supporting per 1000 elderly people- is in the face of stress. Fees of private nursing home are expensive, while the public nursing home are occupied by the elderly holding privilege thus be viewed as a vanity project. And even some nursing homes in China have norms that clearly require the elderly to have children signing in occupancy agreements before staying in, which essentially refuse the lost only-child elderly. In order to change this situation, the government should be strict to manage nursing homes and should take the principle of treating special issues specially and strengthen the protections for the lost only-child elderly who are far more fragile than the general elderly people. Reducing the threshold to stay in the nursing homes for the lost only-child elderly and exempting from the procedures of signature are recommended. At the same time, the preferential policies should be implemented to the nursing homes that accept the lost only-child family such as giving funding subsidies, purchase of new equipment, and reducing the financial burden on the nursing homes for the lost only-child families. Secondly, professional supports should be provided. Regardless of the physical or mental depths, the lost only-child elderly have experienced the pain of losing their only child and had a variety of changes. In this special period, they particularly need the government to offer medical support and psychological counseling and to organize professional doctors to provide medical support, because they belong to high-risk groups and are easier to suffer from a variety of diseases and cancer at constant depression state. On the one hand, the government should provide the lost only-child elderly with regular physical examination and disease prevention and achieve the aim of early detection and early treatment. On the other hand, the lost only-child elderly often appear symptoms of dizziness, indigestion, sleep quality decline and so on, and they are easy to abuse the medication and will bring worse consequences without any care, so they need door-to-door service for ailment and professional nursing service for illness. This requires professional medical staff to provide on-site service supported by special pension funds and the organization of professional psychological counseling experts to conduct psychological counseling for the lost only-child elderly. Pains of the lost only-child elderly lie in losing their closest relatives, feeling lonely and finally losing hope of life. The government should organize professional psychological counseling experts into the lost only-child families to conduct professional and effective psychological treatments for the lost only-child elderly [10], and provide suitable activities according to respective psychological status, such as establish the social support network and the warmth groups for the lost only-child elderly and so on. Through these efforts, the lost only-child elderly will feel the love of the whole society and the government's care and live a new life.

Third, the administrative contract system of pension should be improved. Administrative contract refers to a contract signed by the government departments and the relatives in order to facilitate the implementation of the administrative management. Different from the general civil contract, the subject of administrative in the administrative contract protects the public interest and enjoys the administrative advantage. According to different standards, administrative contract can be classified into different categories, the important one of which is the government procurement contract referring to a purchase agreement that all levels of governments and departments use public funds to buy goods, engineering and service according to the legal procedure for the sake of the public interest needs. The lost only-child elderly have no child to support themselves and can only rely on the government 
and social concern and help. Therefore, it is full of important practical value for the government to purchase pension services. Pension services refers to the service offered to the elderly because of their bodily degeneration or deprivation and requirement for help, whose primary purpose is to solve the problem of life care for the elderly, or to have people to take care of the elderly. With times changing, the pension service meet not only the life physical care demand but the spiritual solace demand. Government procurement contract is not only that the governments purchase pension services from a third party for the elderly who meet certain conditions, but that the governments directly provide the elderly with enough grants and the elderly themselves purchase the service from the third party. The third party, in principle, refers to a professional pension service institutions as well as service providers.

Fourth, the channels of administrative relief for the lost only-child elderly should be broadened. Chinese Constitution clearly stipulates that citizens have the right to material assistance from the state and society when they are old, ill or disabled. The government has an inescapable responsibility for the lost only-child elderly who fall into the pension dilemma because of losing their only child. At the same time, the Population and Family Planning Law also stipulates that local governments should give the lost only-child elderly necessary help. Concerning about the interests of the elderly pension is not only the specific performance of the implementation of the constitutional spirit, but also an important measure of the implementation of the Population and Family Planning Law. Despite the lost only-child elderly can obtain the national pension insurance benefits in accordance with the provisions of the relevant laws, but these provisions are limited to the level of principle, lack of operable regulations, and often fall into embarrassment of single law is too inadequate to carry out in the process of implementation. These are due to some government officials pay little attentions to the lost only-child families on the issue of old-age security system. Therefore, it is suggested under the National Commission on Aging to establish the working groups that work for the lost only-child families, which make the scientific investigation and research on the issue of old-age security for the lost only-child families, play a leading role in the follow-up policy planning and working system, and provide a powerful supporting information and decision-making basis for different departments of its national administration. At the same time, it is recommended to set up the assistance teams for the lost only-child elderly in community, strengthen the grass-roots level service, offer them help in the matter of administrative litigation and administrative reconsideration, and establish a constitution that administers the group of the lost only-child elderly, so that these elderly have somewhere to turn to.

\section{Conclusions}

Chinese Birth Control Policy has led to the existence of vast lost only-child elderly. The lost only-child elderly lack of shelter and care from their own children, so their economic life is poorly off and mental state is vulnerable and sensitive. The lost only-child elderly has risen to a serious social problem. The existence of vast lost only-child elderly and protection gaps are mainly due to defect of the Birth Control Policy, lack of government financial investment and imperfect social security system. Therefore, Chinese government should establish a mechanism to increase and maintain the value of administrative compensations, strengthen administrative pay and protection of administrative contracts, broaden administrative relief channels for the elderly, and effectively protect the pension interests of the lost only-child elderly. 


\section{References}

[1] Fifth Plenary Session of the Eighteen Held in Beijing, People's Daily, 2015-10-30(1).

[2] Li Yan, the Pains of the Lost Alone People: Living and Death at a Wrong Time, Nandu Weekly 2012(27).

[3] Information on http//opinion.huanqiu.com/1152/2012-05/27 16503.html

[4] Information on http://jx.sina.com.cn/news/b/2013-01-25/08 2813798.html

[5] Information on http://china.caixin.com/2013-10-18/100593 559.html
[6] Information on http://www.china.com.cn/policy/txt/2011-12 $/ 28 /$ cont

[7] Information on http://cws.mca.gov.cn/article/tjbg/201210/2 0121000

[8] Zhang Wenxian, Jurisprudence, Higher Education Press \& Peking University Press, pp.146, 2012.

[9] Wang Ke, Study on the Current Situation and Solution to the Problem of the Lost Alone People, Journal of Jilin Radio And TV University, 2013(1).

[10] Information on http://news.163.com/14/0211/02/9KP5BP9 P00014AED.html 